\title{
Going means trouble and staying makes it double: the value of licensing recorded music online
}

\author{
Christian Handke ${ }^{1,2} \cdot$ Bodo Balazs $^{2} \cdot$ Joan-Josep Vallbé $^{2}$
}

Received: 25 July 2014/Accepted: 27 April 2015/Published online: 22 May 2015

(C) The Author(s) 2015. This article is published with open access at Springerlink.com

\begin{abstract}
This paper discusses whether a copyright compensation system (CCS) for recorded music_-endowing private Internet subscribers with the right to download and use works in return for a fee-would be welfare increasing. It reports on the results of a discrete choice experiment conducted with a representative sample of the Dutch population consisting of 4986 participants. Under some conservative assumptions, we find that applied only to recorded music, a mandatory CCS could increase the welfare of rights holders and users in the Netherlands by over $€ 600$ million per year (over $€ 35$ per capita). This far exceeds current rights holder revenues from the market of recorded music of ca. $€ 144$ million per year. A monthly CCS fee of ca. $€ 1.74$ as a surcharge on Dutch Internet subscriptions would raise the same amount of revenues to rights holders as the current market for recorded music. With a voluntary CCS, the estimated welfare gains to users and rights holders are even greater for CCS fees below $€ 20$ on the user side. A voluntary CCS would also perform better in the long run, as it could retain a greater extent of market coordination. The results of our choice experiment indicate that a well-designed CCS for recorded music would simultaneously make users and rights holders better off. This result holds even if we correct for frequently observed rates of overestimation in contingent valuation studies.
\end{abstract}

The first part of this title paraphrases The Clash's "Should I stay or should I go" (Mellor and Jones 1982).

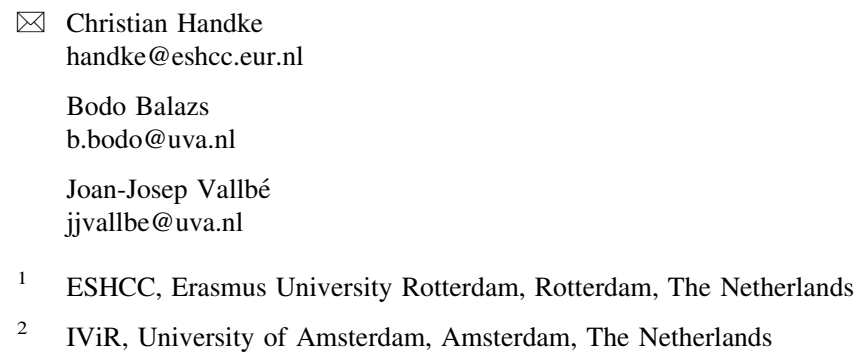


Keywords Copyright - Recorded music - Collective rights management - Internet · Contingent valuation $\cdot$ Compensation systems

\section{Introduction}

A fundamental question in copyright industries is how to cope with the widespread use of digital information and communication technology (ICT) for unauthorized copying. Over 15 years ago, the explosive growth of the file-sharing network Napster put the issue on the agenda of policy makers and stakeholders. So far, neither private nor public copyright enforcement measures have resolved the issue. Copyrights holders face a tough choice between continuing to try and enforce exclusive rights in the digital realm or exploring alternatives, such as the one discussed in this paper.

This paper discusses whether a copyright compensation system (CCS) for recorded music - endowing private Internet subscribers with the right to download and use works in return for a fee-would be welfare increasing under current market conditions. It reports the results of a discrete choice experiment conducted with a representative sample of the Dutch population consisting of 4986 participants. The Internet penetration rate in the Netherlands is $95 \%$, one of the highest worldwide (Eurostat 2014a, b). The Netherlands also entertains a system of levies on copying technology, so that basic elements of a CCS should be familiar to many residences.

We find that applied only to recorded music, a mandatory CCS could increase the welfare of rights holders and users in the Netherlands by over $€ 600$ million per year (over $€ 35$ per capita). This far exceeds the current sales value of recorded music of ca. $€ 144$ million. Even if a CCS were to substitute all of the current sales of recorded music and provided no cost-savings, it could simultaneously increase user welfare and rights holder revenues at a price that constitutes a reasonable surplus split. According to our results, this is achieved over a broad range of CCS user fees, for example between ca. €1.74 and €9.25 for a CCS that is mandatory for all households with Internet subscription.

Some market conditions in the Netherlands make this result particularly noteworthy. On the one hand, during data collection, unauthorized private copying from unlawful sources was not outlawed in contrast to some other European countries. On the other hand, the digital market for recorded music in the Netherlands is relatively advanced. In 2012, the year preceding data collection, the digital market in the Netherlands already accounted for $31 \%$ of all revenues in the primary market for recorded music, in which authorized services make copies of recordings available to end users (IFPI 2013). Given lower average retail prices for digital copies, the share of "digital" in unit sales would be higher. Music subscription services and ad-supported online music services accounted for $54 \%$ of digital revenues. ${ }^{1}$ Residents of the Netherlands thus report substantial willingness to pay (WTP) for participation in a compensation system covering recorded music, in

\footnotetext{
1 Extrapolating recent trends, the share of the digital market was probably greater in November 2013, when data were collected (IFPI 2013).
} 
spite of (1) virtually no legal risk associated with private copying from unlawful sources at the time of data collection, and (2) availability and widespread use of authorized digital music services and in particular music subscriptions.

The paper is structured as follows: Sect. 2 briefly discusses digitization in the copyright industries and the literature on CCS. Section 3 describes the application and limitation of contingent valuation methods to value untraded goods and discrete choice experiments in particular, and provides information on the method and data used in this paper. Section 4 describes basic results, and Sect. 5 presents estimates of the effect of several CCS options on user welfare and rights holder revenues. Section 6 discusses a number of limitations and extensions to our assessment. Section 7 presents main conclusions.

\section{Literature}

\subsection{The economics of copyright and digitization}

Copyright works are quasi-public goods: important aspects of them are hard to exclude and non-rival in consumption. ${ }^{2}$ Copyright works are information goods with the typical cost structure of high, sunk development costs compared to low costs of reproduction and dissemination. According to basic economic theory, this is associated with market failure due to insufficient social coordination in the provision of public goods. Individually, rational users will opt for unauthorized use without compensating rights holders. Many investing in socially efficient creation and authorized dissemination of copyright works are unable to recoup sunk costs. In the short run, regarding existing creative works, unrestricted use is socially optimal (Arrow 1962), since establishing exclusive rights and trading of rights generates a deadweight loss. In the long run, insufficient incentives to supply quasi-public works may be associated with misallocation and welfare loss. A CCS is one way to develop a compromise between the underutilization of existing works and the underproduction of new creative works (Novos and Waldman 1984).

The diffusion of digital ICT aggravates the public good attributes of reproducible creative works. The most apparent effect of digitization is to lower the costs of reproduction and dissemination of copyright works. The costs of creating new works also fall but-due to the labor-intensive nature of the creation process (Baumol and Bowen 1966)_remain substantially higher than the costs of reproduction and dissemination.

Most private and public enforcement initiatives, such as technical protection measures, litigation-based enforcement, or graduated response systems, have not been cost-efficient. They conflict with the privacy of information exchanges online and raise difficult questions about the responsibility of Internet service providers

\footnotetext{
${ }^{2}$ Fundamental contributions to the economics of copyright are Novos and Waldman (1984) and Landes and Posner (1989). A recent literature survey is Towse et al. (2008). Peitz and Waelbroeck (2006) discuss the economic theory of piracy. Recent literature reviews regarding the empirical literature on copying and copyright are Handke (2012) and Watson et al. (2014).
} 
(ISP) regarding copyright infringements by users of their services. There are also problems in enforcing national law online.

One of the greatest challenges in estimating the welfare effect of any copyright system is developing a measure of the value of the creative works supplied because of copyright. We find that there is ample scope for CCS to simultaneously increase user welfare and rights holder revenues. Making the basic assumption that the law of supply holds for copyright works - in the sense that greater revenues to rights holder will result in greater supply of valuable, new creative works - any CCS that generates greater rights holder revenues would thus have dynamic benefits. The welfare gains estimated in this paper would be sustainable. Whether there would be additional dynamic benefits depends on the extent to which participants in the choice experiment managed to incorporate long-run effects on the supply of works into their evaluation.

\subsection{Copyright compensation systems}

The basic idea of CCS is to reward rights holders for unauthorized use of copyright works, where either the enforcement of exclusive rights and by extension direct market transactions between rights holders and users are too costly; see Handke et al. (2013) for an extensive discussion and literature review. More or less detailed suggestions of CCS include Lunney (2001), Ku (2002), Netanel (2003), Fisher (2004), Eckersley (2004), and Aigrain $(2008,2012){ }^{3}$

Private copying levies (PCL) on copying hardware are a type of CCS that already exists in the USA, Canada, and the majority of European countries. For an overview across numerous countries, see WIPO (2013). However, in most countries, PCL do not legalize copies made from so-called unlawful sources, such as peer-to-peer networks. In the Netherlands, copies from unlawful sources were not explicitly excluded when we collected data in 2013; the issue was contentious at the time, and later jurisdiction has clarified that copies from unlawful sources are not covered by domestic PCL. ${ }^{4}$ The scale and scope of private copying levies tends to be greatest in Europe. While levies do often apply to ICT hardware, no levies have yet been introduced to Internet subscription.

CCS does not establish an obligation to pay copyright royalties with acquisition or use of works, which is difficult to monitor. We discuss CCS options that apply to Internet subscription, as suggested for example by Netanel (2003) and that include copies from many sources that are "unlawful" at this time..$^{5}$ The CCS would endow participating users with the right to download copyright works from the Internet and use them for non-commercial purposes, in return for a surcharge on Internet subscriptions. We vary a number of other CCS options in our empirical work, see Sect. 3.

\footnotetext{
3 Widely discussed commissioned reports include Modot et al. (2011) and Spindler (2013).

${ }^{4}$ See the ruling of the Dutch Hoge Raad der Nederlanden in the case ACI Adams versus Stichting de Thuiskopie; online: http://curia.europa.eu/juris/liste.jsf?num=C-435/12.

5 Netanel (2003) suggests levies similar to PCL but applied to Internet subscription. Eckersley (2004) and Fisher (2004) discuss taxation. Ku (2002) suggests revenue sharing between copyrights holders and suppliers of goods and services that are frequently used to disseminate works.
} 
For rights holders, the most direct benefit of a CCS is that it generates income associated with unauthorized uses online. A CCS can also reduce all types of transaction costs for rights holders and users, by standardization and bundling of transactions (see the following discussion of collective rights management). For users, the most direct benefit of a CCS is that it reduces legal risks when accessing or disseminating copyright works online. ${ }^{6}$ Effective compensation of creators/rights holders could also benefit users. First and foremost, compensation of rights holders could mitigate any problem with underproduction of non-excludable creative works. Furthermore, survey data consistently suggest that users do have a preference for compensating creators (e.g., Rochelandet and le Guel 2005; Hennig-Thurau et al. 2007; Fetscherin 2009). A CCS could thus be a benefit to users in its own right. A CCS could also mitigate costly social conflict over copyright, including the burden on the taxpayer from litigation.

In essence, CCS is an extension of collective rights management that is a longstanding practice in parts of the market for copyright works. CCS differs from a situation with direct transactions between rights holders and users in two ways. On the one hand, a CCS generates a blanket license covering a large repertoire of works from many rights holders and establishes standardized terms of use, reducing the scope for individual bargaining. On the other hand, a CCS requires an intermediary organization that sets these standard terms and administers copyrights.

Standardization of prices and other terms of use is a two-edged sword (Blind 2004). On the one hand, it can reduce transaction costs compared to direct transactions between individual suppliers and users-including monitoring and enforcement costs but also search, bargaining, and contracting costs. On the other hand, standards are associated with less flexibility and offset the market mechanism. Economists have been critical of CCS in particular because it restricts price setting through the market with a less adaptive standard and may thus be associated with misallocation of resources (Liebowitz 2003, 2005; Merges 2004; Liebowitz and Watt 2006). A CCS standard reduces the scope for tailoring prices and terms of trade to the specific situation of individual rights holders and users. It may inhibit adaptations to changing market conditions over time. This holds in particular where CCS participation is mandatory for users and/or rights holders. Therefore, we also discuss voluntary CCS on the user side, which are more efficient in this respect.

Furthermore, a CCS requires a copyright management organization (CMO) that fulfills similar functions of existing collecting societies. The economics of CMO are discussed in Besen and Kirby (1989), Besen et al. (1992), Watt (2000), Handke and Towse (2007), and Handke (2014). Functions of CMO are to set prices and standard terms, monitor use of copyright works, collect royalties, and distribute them among rights holders. Existing CMO tends not to provide sorting functions, which has received much attention in the microeconomics of intermediation: They do not provide signals of quality to users by including works based on the assessments of quality. Instead, they exploit economies of scale in the administration of copyrights,

\footnotetext{
6 To be sure, in the Netherlands, legal risks associated with unauthorized use for private purposes were very limited at the time when data were collected. However, it was also clear that stronger copyright enforcement could be introduced in the foreseeable future in response to rights holder lobbying and international legislation affecting the Netherlands.
} 
and they reduce the number of transactions, where rights holders and users with multiple potential trading partners only interact with the CMO.

Running a CMO is costly, however. Due to economies of scale and network effects associated with rights administration, CMO may enjoy extensive market power both on the rights holder and user side, requiring regulation. As large organizations with multiple stakeholders, CMO may also exhibit inertia and slow decision making.

Another problem associated with collective rights management is that a CMO would have to distribute royalties among rights holders based on incomplete information on actual use. The CMO would have to develop a system to monitor use online among a representative sample of users (monitoring all users probably being too costly and raising similar privacy issues as those associated with conventional copyright enforcement). The same problem does not occur with direct transactions between rights holders and users. Yet, the very reason that a CCS is of interest is that rights holders have found it prohibitively costly to control use. That is, an effective CCS will increase rights holder revenues but may distort the market if its distribution of revenues is less proportional to actual use of copyright works than with direct transactions.

Summarizing these arguments regarding the efficiency of CMO and CCS in particular, Handke et al. (2013) speak of a simplicity-flexibility trade-off. CCS simplifies markets by limiting the options of market participants and associating royalty payments with activities that are more easily monitored than the nature of information exchanges online.

Neither the status quo with frequent unauthorized use and costly copyright enforcement measures, nor a CCS with standardized terms of use and a central intermediary are first-best options. Overall, it is an empirical question whether CCS would increase social welfare compared to the status quo.

\section{Methods}

\subsection{Contingent valuation through discrete choice experiments}

The debate on CCS suffers from a lack of credible empirical evidence. Noteworthy empirical work on CCS includes Karaganis and Renkema (2012), Entertainment Media Research (2011), and STIM (2012). They all find that a substantial share of the respective samples report willingness to pay (WTP) equivalent to several Euros per month for some type of license to access copyright works online with fewer legal restrictions than today. All of these studies are limited in two respects: First, they only cover a narrow range of CCS options; second, the methods of eliciting WTP differ from the recommended standard of contingent valuation of untraded goods (Alberini and Kahn 2009; Arrow and Solow 1993; Bateman et al. 2002; Throsby 2003).

We conducted a discrete choice experiment covering a wide range of CCS options. We are thus able to identify and focus on more promising combinations of 
CCS attributes, and to develop measures of WTP and the welfare implications of these options using state-of-the-art methods in contingent valuation.

Conjoint analysis (CA) has in the last two decades established itself as a robust and well-tested survey method to elicit reliable marginal WTP for different attributes and attribute levels of complex products. Besides its widespread commercial use, it is increasingly utilized in policy research. Discrete choice experiments are among the best methods to evaluate goods that are untraded, either because they have not been released to markets or because they have public good attributes (Bateman et al. 2002; Harrison and Rutström 2008). ${ }^{7}$ They best resemble real market choices and reduce the scope for strategic responses. See Noonan (2003) for a meta-study of contingent valuation studies regarding the cultural sector.

As with any stated preference method, results have to be interpreted with caution. Most importantly for the topic at hand, contingent valuation surveys tend to overestimate WTP. The influential Oceanic and Atmospheric Administration's (NOAA 1996) blue-ribbon panel recommended division by 2 if data cannot be calibrated against real market data. In two widely cited meta-studies, Little and Berrens (2004) and Murphy et al. (2005a, b) estimated central tendencies in a number of contingent valuation applications. Mean bias was overestimation of WTP by a factor of 3.13 for the former and 3.26 for the latter paper. The median in Murphy et al. (2005a, b) was much lower at 1.50; however, much of the mean overestimation is due to a minority of studies dealing with high-value goods.

Our choice experiment combines aspects that have been associated with high overestimation in previous studies, as well as aspects that have been associated with low overestimation. First and foremost, Murphy et al. (2005a, b: 323) find: "For smaller hypothetical values that are common in CV studies, our results suggest that hypothetical bias may not be a major problem." In their analysis, WTP overestimation in contingent valuation studies increases exponentially with payment amounts. ${ }^{8}$ On average, they find no overestimation for hypothetical values up to US\$10 and overestimation rises to two for hypothetical values of US\$32.50. The amounts covered in this survey are relatively low, ranging between $€ 5$ and $€ 30$. By itself, this should be associated with lower overestimation compared to the average across all contingent valuation studies included in meta-analyses, even though some uncertainty remains due to a large variance of overestimation. What is more, we used a discrete choice referendum design, which is associated with significantly lower overestimation in meta-studies (List and Gallet 2001; Little and Berrens 2004; Murphy et al. 2005a, b).

\footnotetext{
7 CCS for online use of copyright works has not been adopted in any relevant market. CCS has public good attributes, since they facilitate the financing of the production of non-excludable creative works.

${ }^{8}$ Murphy et al. (2005a, b: 323) find that "the evidence is quite strong that there is a positive quadratic relationship between hypothetical values and hypothetical bias." Hypothetical values in studies covered by Murphy et al. (2005a, b: 316) range between .08 and 301, with a mean of 26.55. The regression coefficient for hypothetical bias (overestimation) with hypothetical value as independent variable is .498 and significant at the $1 \%$ level. With the square of hypothetical value as the independent variable, the coefficient is .046 and significant at the $10 \%$ level $(n=77)$. Murphy et al. (2005a, b) do not distinguish currencies, which complicates the interpretation. Nominal values are probably less important than purchasing power or the share of the hypothetical value in disposable income.
} 
On the other hand, a CCS license is an unfamiliar and complex quasi-public good that is challenging to evaluate. Choice experiments tend to produce more valid results regarding WTP if results are presented as directly affecting policy (consequentiality). For ethical considerations, we were unable to pretend to participants in the choice experiment that there were specific plans to introduce a CCS in the Netherlands, which may be associated with relatively great hypothetical bias. Due to concern with the overall length of the questionnaire, no "cheap talk" design was adopted. ${ }^{9}$ In the following, we first report the pure empirical results and relate these to typical overestimation rates in the conclusions.

\subsection{Data collection}

In the choice experiment, the payment mechanism of the CCS was defined as a surcharge to the Internet subscription payment, which would be associated with least transaction costs among users. Respondents were informed that the operations of the CCS and the distribution of revenues would occur under statutory regulation.

Respondents were randomly assigned to different treatments. See Fig. 1 for an overview, which highlights the treatments and attribute expressions considered in this paper. The CCS was defined as either mandatory for all Internet subscribers, or as voluntary so that users could decide themselves whether to pay the fee and acquire the CCS license. The voluntary scenario had two subtypes: one, where the enforcement of copyright among private end users was to be strengthened among users opting out of the CCS, and one where no change to copyright enforcement was mentioned. Regarding pricing, we distinguished between a single, fixed CCS license fee and metered pricing in the choice experiment. We focus on results for the flat CCS fee throughout this paper.

In the conjoint survey proper, the following CCS attributes and attribute expressions were varied ${ }^{10}$; see Appendix 1 for an overview of the formulations exhibited in the choice experiment:

\subsubsection{Allowed uses}

This attribute covers the rights provided by a CCS to the participating users. It has three levels: (1) downloading only; (2) downloading and sharing, covering the rights of making accessible and communication to the public; and (3) downloading, sharing, and modification, covering the right to create and disseminate derivative works.

\footnotetext{
9 "Cheap talk" scripts inform respondents of hypothetical bias and exaggerated reports of WTP in contingent valuation methods, and remind respondents to avoid overstating their WTP. This method has only been found effective in reducing WTP overestimation for larger payment amounts. Abbreviated "cheap talk" scripts have been associated with greater overestimation (Murphy et al. 2005a, b).

10 See Quintais (2013) for an excellent overview and legal analysis that inspired the development of attributes for this survey.
} 


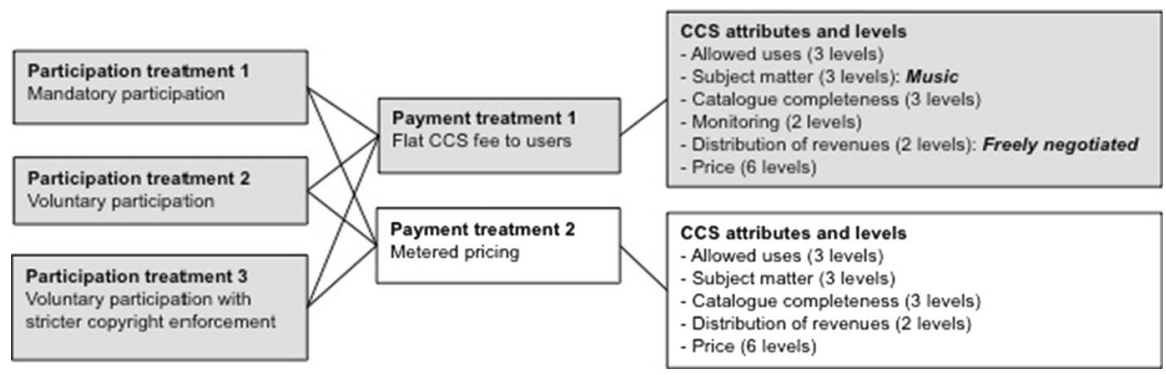

Fig. 1 Overview of treatments and conjoint aspects of the discrete choice experiment

\subsubsection{Subject matter}

This attribute also has three levels: (1) recorded music only; (2) recorded music and audiovisual works; and (3) recorded music, audiovisual works, and books. We focus on the results for recorded music in this paper.

\subsubsection{Catalogue completeness}

This attribute concerns the extent to which a CCS license covers existing works. The three levels are: (1) complete catalogue; (2) temporal restrictions, e.g., novelties only being covered after a delay; and (3) incomplete catalogue, referring to permanent limitations in the coverage of the CCS license.

\subsubsection{Monitoring}

With metered pricing, personalized monitoring is necessary to establish the price an individual user is to pay. With fixed pricing, some monitoring is required to develop an efficient distribution of CCS revenues among rights holders, which can be achieved through anonymized monitoring of a random sample. For the fixed payment option, we thus addressed the issue of monitoring through two levels: (1) any CCS participation is associated with monitoring of user behavior and anonymized analysis; (2) there is explicit mention of a statutory guarantee of no monitoring.

\subsubsection{Distribution of revenues}

This attribute has two levels: (1) The CCS contains a statutory guarantee that original creators receive at least $50 \%$ of the CCS revenues; (2) original creators are free to negotiate the revenue split with investors or intermediaries (such as publishers or record companies).

\subsubsection{Price}

The choice experiment covers six equidistant price points from $€ 5$ to $€ 30$. 
For the conjoint analysis aspect of choice experiment, we created an efficient choice design with 54 choice sets, 27 for the fixed payment scenario and 27 for the metered payment scenario. Respondent were randomly presented with 12 choice sets that each consisted of two, utility balanced CCS options and a "choose none" option.

\subsection{The sample}

We conducted the choice experiment on the Longitudinal Internet Studies for the Social Sciences (LISS) panel, a longitudinal panel survey comparable to the Panel Study of Income Dynamics (PSID) in the USA or the German Socio-Economic Panel (SOEP). For a documentation of the LISS panel, see CentERdata (2014). The panel consists of a representative sample of the Dutch population (including those without Internet connection). Panel members complete an online questionnaire every month, and our questions were incorporated into the questionnaire of November 2013. Panel members are paid for each completed questionnaire. ${ }^{11}$ Our survey was reviewed, programmed, and conducted by the panel administrator CentERdata. Our sample was comprised of all 6216 active panel members at the time aged 16 years or older. The participation rate was $79.9 \%$, and 4858 respondents $(78.2 \%)$ completed the choice experiment and responded to all other survey questions (completion rate: $78.2 \%$; incomplete: $1.7 \%$ ). This turnout and results for follow-up questions regarding the comprehensibility of the questionnaire were better than average for questionnaires delivered through the LISS panel. ${ }^{12}$

\subsection{Choice modeling}

Attribute-based discrete choice models such as conjoint analysis are based on random utility theory (McFadden 1974) and Lancaster's theories of demand and consumer theory (Lancaster 1966, 1971). They are compatible with both utility maximization by decision makers (Train 2003) and utility decomposition by alternative attributes or characteristics (Loureiro and Umberger 2007). Following Train's (2003) canonical exposition, a decision maker, $n$, faces a choice among $J$ alternatives, from each of which she can obtain certain levels of utility. The utility that decision maker $n$ obtains from alternative $j$ is $U_{n j}, j=1, \ldots, J$, and she chooses the alternative that yields highest utility, so alternative $i$ will be chosen if and only if $U_{n i}>U_{n j} \quad \forall j \neq i$.

The assumption is that the decision maker knows the utility provided by each alternative. The model, though, does not account for the direct observation of such utility but only of certain attributes of the alternatives, $x_{n j} \forall j$ and some

\footnotetext{
11 Where necessary for participation, LISS panel members are provided with suitable ICT.

12 There are indications of potential non-response bias. Non-respondents are significantly younger, still studying, or being autonomous professionals, freelancers, or self-employed, still living with their parents or with their unwedded partners in larger cities. It seems the "digital natives" are thus underrepresented in our sample. On the other hand, older, widowed people, and those living in rural environment are overrepresented. Since the latter characteristics correlate with a low probability of accepting any CCS option, this is probably a source of underestimation of WTP in our data.
} 
characteristics of the decision maker, $m_{n}$. There are unobserved features of utility, so that $U_{n j} \neq V_{n j}$, and utility has an observed and an unobserved component, $U_{n j}=V_{n j}+\varepsilon_{n j}$, where $\varepsilon_{n j}$ represents the difference between the actual utility $U_{n j}$ and the utility captured by $V_{n j}$. The error term of the model, $\varepsilon_{n j} \forall j$, is unknown quantity and treated as a random variable. The vector of all values of the unobserved component for all alternatives is $\varepsilon_{n j}=\left\{\varepsilon_{n 1}, \ldots, \varepsilon_{n J}\right\}$ and has density $f\left(\varepsilon_{n}\right)$, with which we can make probability statements about the choice of the decision maker. Then, the probability that the decision maker $n$ chooses alternative $i$ is:

$$
\begin{aligned}
P_{n i} & =\operatorname{Prob}\left(U_{n i}>U_{n j} \quad \forall j \neq i\right) \\
& =\operatorname{Prob}\left(V_{n i}+\varepsilon_{n i}>V_{n j}+\varepsilon_{n j} \quad \forall j \neq i\right) \\
& =\operatorname{Prob}\left(\varepsilon_{n j}-\varepsilon_{n i}<V_{n i}-V_{n j} \quad \forall \quad j \neq i\right)
\end{aligned}
$$

This probability is a cumulative distribution, and using the density $f\left(\varepsilon_{n}\right)$ and assuming that each $\varepsilon_{n j}$ is independently, identically distributed extreme value, we obtain the basic conditional logit model, where the probability that a decision maker chooses alternative $j$ (in a choice set $K$ ) containing $z$ attributes is:

$$
P\left(y_{n}=j\right)=\frac{\exp \left(z_{j}\right)}{\sum_{j \in K} \exp \left(z_{J}\right)}
$$

with $z_{j}=\beta x_{j}$, where $x_{j}$ is the value of the attribute $x$ for alternative $j$ and coefficient $\beta$ represents the effect of $x$ on the choice of an alternative in a choice set $K$.

Using Elff's (2013) mclogit algorithm for the R statistical programming language (R Core Team 2014), we fit a conditional logit model of choice on the six different attributes described above. Following Haaijer et al. (2001), a no-choice constant is included to reduce potential bias in the estimates for the attributes. The empirical specification of our model is:

$$
U_{n j}=\beta_{1} \mathrm{AU}+\beta_{2} \mathrm{SM}+\beta_{3} \mathrm{CC}+\beta_{4} \mathrm{MT}+\beta_{5} \mathrm{DR}+\beta_{6} \text { Price }+\beta_{7} \mathrm{NC}+\varepsilon_{n j}
$$

where the variables affected by the coefficients $\beta_{1}$ to $\beta_{6}$ stand for the six different alternative-specific attributes (e.g., AU = allowed uses, $\mathrm{SM}=$ subject matter), $\mathrm{NC}$ is the constant for the no-choice option, and $\varepsilon_{n j}$ is the unobserved, error term. The model can provide (1) logistic coefficients that point to the marginal effect of changes in attribute levels on the indirect utility $U_{n j}$; (2) the WTP associated with a change in an attribute level in price terms-i.e., the ratio between the parameter of the attributes and the price parameter; and (3) average probabilities of acceptance for all alternatives, so that it is possible to post-estimate these probabilities at different price points.

\section{Basic results of the choice experiments}

Appendix 2 presents the parameter estimates for all attribute expressions and for the various subsamples, within the fixed payment treatment, including filmed entertainment and books. Regardless of the type of participation, on average, 
respondents show preference for being able to download a package of content including music and audiovisual material from a temporally restricted catalogue, without monitoring, without a guaranteed minimum share of original creators in revenues, and at a low price. Sensitivity toward price is very stable across all subsamples, but attributes such as the allowed uses, the completeness of the catalogue, and payment of artists show interesting patterns. For instance, a complete catalogue provides respondents with significantly higher utility than a partial catalogue when participation in the CCS is mandatory, while the effect of this change in attribute levels approaches zero or simply dissipates when participation is voluntary, with or without strict enforcement. ${ }^{13}$

Following the standard procedure (e.g., Telser and Zweifel 2002; Lagerkvist et al. 2006), we compute estimates of the marginal WTP associated with changes in each attribute by dividing each attribute's marginal utility by the price coefficient.

In this paper, we are focusing on a specific range of CCS options. We consider only recorded music. We only assess a fixed price charged on the user side, which would be easier to implement than metered pricing. We only consider freely negotiated revenue sharing between original creators and other rights holders, as the discussion of CCS pricing that would fully compensate rights holders is more complicated with regulation of revenue shares. Within the range of remaining options, we identify the most valuable CCS option that covered in the choice experiment, and check whether it would simultaneously increase rights holder and user welfare. We also compare results between a situation in which this CCS option is mandatory or voluntary on the user side.

In order to rank alternatives by their popularity among respondents, we used two alternative methods. First, we calculated the times each unique combination of attributes (i.e., each alternative) was chosen relative to the times the combination of attributes was presented in choice sets. Second, from the conditional logit results, we predicted the probability of acceptance of each alternative presented in each choice set, from which we derived average probabilities for each unique alternative. Both methods yielded the same result regarding the most popular option. In particular, respondents showed most preference for the combination of attributes that included: (1) the right to download and share (AU = download and share); (2) only music ( $\mathrm{SM}=$ music); (3) from a catalogue with temporal restrictions $(\mathrm{CC}=\text { temporal restrictions })^{14}$; (4) with fixed revenue guaranteed to artists (PA = guarantee); (5) with no monitoring (MT = no monitoring); and (6) at a price of $€ 5$. This is our alternative of reference.

We estimate the probability of acceptance of this CCS option as an alternative to the status quo for all six price points covered in the choice experiment. We simulate six artificial choice sets in which the most preferred alternative competes with the

\footnotetext{
13 Further analyses should model the heterogeneity of individual preferences due to differences in age, income, or online consumption.

14 Higher mean WTP for a CCS with temporal restrictions may be counterintuitive. The choice experiment did encourage participants to reflect on their assessment regarding long-run consequences of unauthorized copying and the position of rights holders. In this context, it is rational for users to prefer CCS that strikes a compromise between immediate user interests and the position of rights holders.
} 
no-choice option, which stands for the status quo. At each choice set, the preferred option is presented at a different price level. We use pair-wise confrontation of alternatives - instead of the three-alternative choice set model used in the actual choice experiment - to give the choice situation a closer resemblance to a realworld choice in which a single CCS policy is presented to a user.

Table 1 and Fig. 2 present the distribution of predicted probabilities of acceptance of the CCS alternative against the status quo and at the different price levels. As is to be expected, the probability of user acceptance is strictly decreasing in price. The probabilities of acceptance under each treatment are predicted from each separate conditional logit model under the three types of participation (see results in the Appendix 2).

\section{Effects of a CCS on user and rights holder welfare}

This paper is concerned with the basic question whether any CCS option would simultaneously increase the user and rights holder welfare. For this purpose, we adopt a conservative approach: For several parameters for which there is no precise measure available, we deliberately pick values that will not result in overestimation of welfare gains through a CCS. By concentrating on recorded music, we do not address the desirable scope of a CCS across different types of copyright works. Nor do we address the fine-tuning of the CCS in terms of product differentiation or price discrimination, both of which would be costly to implement but might increase aggregate user welfare and in particular the position of rights holders.

One of the fundamental decisions regarding a CCS is whether it is mandatory or voluntary on the user side. "Mandatory" refers to a CCS where user payment/participation is bundled with Internet subscription; the two are not available separately. "Voluntary" refers to a CCS where user participation is voluntary in the sense that Internet subscribers get to choose whether they want to buy a CCS license. A mandatory CCS is an effective way to inhibit free-riding and thus improve the provision of quasi-public goods. The disadvantage is that a mandatory CCS offsets the market coordination between supply and demand. This has been the main criticism of CCS raised in the economics literature so far (Merges 2004; Liebowitz 2005). A voluntary CCS provides users with greater flexibility. When users can opt out of the CCS, rights holder income from the CCS depends on the demand for such a license and thus on the utility of licensed works for users. A voluntary CCS is less effective in inhibiting free-riding, however, when coupled with limited copyright enforcement. Due to these differences, it is not certain whether rational users would prefer mandatory or voluntary CCS. The calculation of the welfare implications of mandatory and voluntary CCS is distinct, and we present them separately.

\subsection{A mandatory compensation system}

No mandatory CCS will be generally welfare increasing. Among users, WTP is too varied, many users have a WTP of zero, and price discrimination and/or product 
Table 1 Predicted probability of acceptance (WTP $\geq$ price) of a CCS at different price levels and under three treatment conditions (SE in parenthesis)

\begin{tabular}{llll}
\hline Price $(€ /$ month) & $\begin{array}{l}\text { Mandatory } \\
\text { Probability (SE) }\end{array}$ & $\begin{array}{l}\text { Voluntary } \\
\text { Probability (SE) }\end{array}$ & $\begin{array}{l}\text { Voluntary stricter } \\
\text { Probability (SE) }\end{array}$ \\
\hline 5 & 0.4532 & 0.4464 & 0.4457 \\
& $(0.0138)$ & $(0.0138)$ & $(0.0135)$ \\
10 & 0.3892 & 0.3851 & 0.3810 \\
& $(0.0138)$ & $(0.0138)$ & $(0.0134)$ \\
15 & 0.3287 & 0.3272 & 0.3202 \\
& $(0.0138)$ & $(0.0137)$ & $(0.0133)$ \\
20 & 0.2734 & 0.2741 & 0.2650 \\
& $(0.0136)$ & $(0.0136)$ & $(0.0131)$ \\
25 & 0.2244 & 0.2267 & 0.2163 \\
& $(0.0132)$ & $(0.0133)$ & $(0.0126)$ \\
30 & 0.1819 & 0.1855 & 0.1744 \\
& $(0.0126)$ & $(0.0127)$ & $(0.0119)$ \\
\hline
\end{tabular}
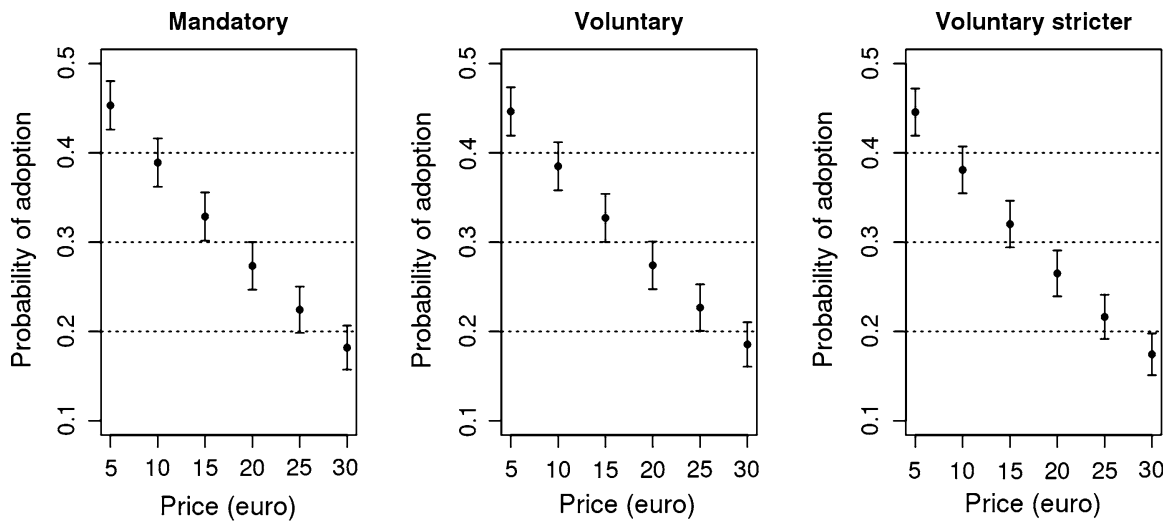

Fig. 2 Predicted probability of acceptance (WTP $\geq$ price) of a CCS at different price levels and under three treatment conditions, with $95 \%$ confidence intervals

differentiation will be restricted in practice. ${ }^{15}$ Median user WTP for any CCS option covered is to reject it $(\mathrm{WTP}<€ 5)$. Mean WTP marks the maximum price at which the CCS option would pass the Kaldor-Hicks compensation test regarding only users, leaving users at large no worse off than under the status quo. We first calculate the aggregate user value and the potential revenues that could be generated

\footnotetext{
${ }^{15}$ In this paper, we focus on a uniform charge for a CCS user license. Price discrimination and product differentiation is tricky because some social groups with below-average income-and thus probably the greatest disutility of a CCS fee-such as students or (young) unemployed - are on average more engaged with unauthorized copying.
} 
by the CCS option. Then, we deduct estimated costs of operating the CCS, to gauge the amount distributed among rights holders. We compare estimated CCS revenues to rights holder revenues under the status quo, in order to establish whether the CCS would increase rights holder profits. We can thus establish whether a CCS would provide a Pareto improvement in the broad sense of simultaneously making users and rights holders at large better off.

Later on, we discuss a number of extensions regarding the substitution of a CCS for conventional purchasing of recorded music; the potential for product differentiation and price discrimination; long-term effects; and the position of other stakeholders, including the effect on demand for Internet subscriptions, which could affect the impact of a CCS on social welfare.

Under a CCS that is mandatory on the user side, there will be two types of participating users ${ }^{16}$ : those with a WTP greater than the price being charged and those with a WTP lower than the price being charged. ${ }^{17}$ The price of a CCS charged among users establishes the division of any surplus among users and rights holders. The net welfare effect of a mandatory CCS for users is

$$
\pi_{U A m}=(\bar{w}(A)-p) N(p, A, X)
$$

where $\pi_{U A m}$ is the accumulated welfare of users, $U$, of a compensation system with the attributes $A$, and the additional subscript $m$ denominating mandatory participation on the user side. The mean WTP reported in the discrete choice experiment is $\bar{w}$, which depends on the characteristics of a CCS, $A$. The price of the CCS license for users is $p$. The number of households with Internet subscription in the Netherlands is $N$. The number of Internet subscriptions is used-rather than the number of individuals aged 15 or older-to avoid overestimation: The payment mechanism described in the discrete choice experiment was a surcharge coupled with the payment for Internet subscription. In multi-person households, one Internet subscription is typically shared by all members of the household, so that respondents may have considered the WTP for a CCS for all household members rather than their individual valuation of a CCS. $N$ depends on the price and attributes of the CCS, as well as the price and attributes of Internet services associated with the CCS, $X$. We assume $X$ is unaffected by the CCS, and we relegate the discussion of demand for Internet subscription for later.

Users with a lower WTP than the price will suffer under a mandatory CCS, whereas those with a higher WTP will benefit. To prepare for a comparison with a voluntary CCS, a separate assessment of users who gain and users who lose is of interest. Equation 1 can be extended to

\footnotetext{
${ }^{16}$ We are assuming a great number of users being distributed in terms of their WTP over a continuous probability function starting at zero (and a spike at zero), and the price of the CCS being lower than the maximum WTP in the population of users (the upper bound of the support). We thus focus on the individual position of users and exclude any disutility that users may have from others participating in a CCS.

${ }^{17}$ For simplicity, we ignore any users with a WTP that is equal to price. Indifferent users cancel out of the welfare analysis.
} 


$$
\pi_{U A m}=\left(\bar{w}_{h}(A)-p\right) n_{h}(p, A, X)-\left(\bar{w}_{l}(A)-p\right) n_{l}(p, A, X)
$$

where subscript $h$ denominates users with a WTP higher than $p$, and subscript $l$ denominates users with a WTP lower than $p$.

To establish the welfare effect of a CCS on rights holders, the relevant comparison is that between total rights holder profits under the status quo and prospective profits under a CCS. Our focus is on estimating monetary rewards from sales of copies to users rather than non-monetary rewards or rights holder profits from markets for related goods and services. This partial measure of welfare of rational rights holders, $\pi_{R}$, is the difference between total revenues/ income of rights holders, $I$, and total costs suffered by rights holders, $C$, that is $\pi_{R}=I-C$.

The effect of a CCS on rights holder welfare compared to the status quo is

$$
\pi_{R A}=\left(I_{A}-C_{A}\right)-\left(I_{S}-C_{S}\right)-B=I_{A}-I_{S}-C_{A}+C_{S}-B
$$

where subscript $S$ stands for status quo, subscript $A$ for a specific combination of CCS attributes, and $B$ stands for the operating costs of the CMO, assuming that the CMO covers its costs by a deduction from collected royalties. This is the predominant way of financing existing CMO so that the operating costs of that organization reduce rights holder revenues rather than increase their costs. For simplicity and since $B$ is probably small, we assume $B$ to be a constant share of the collection amount independent of the number of rights holders, users, and thus of the price charged. ${ }^{18}$ A CCS will not decrease rights holder profits if

$$
I_{A}-C_{A}-B \geq I_{S}-C_{S}
$$

Data on rights holder revenues are accessible, whereas information on costs and thus profits is not. We focus on estimating revenues for now and will discuss costs separately below. Rights holder revenues with a mandatory CCS on the user side associated with Internet subscription are

$$
I_{A m}=p N(p, A, X)-B
$$

Overall, the short-run effect of a mandatory CCS on the welfare of both types of stakeholders, $\Pi_{A m}$, is

$$
\Pi_{A m}=\pi_{U A m}+\pi_{R A m}
$$

Substituting $\pi_{U A m}$ and $\pi_{R A m}$ for their specifications in Eqs. 1, 3, and 5 results in

$$
\Pi_{A m}=(\bar{w}(A)-p) N(p, A)+p N(p, A, X)-I_{S}-C_{A m}+C_{S}-B
$$

We adopt a conservative approach in estimating mean WTP, given that we only have information on a limited number of price points and no empirical estimates of

\footnotetext{
18 The distribution rate of the main CMO concerned with recorded music in the Netherlands, Buma/ Stemra, was $95 \%$ in 2013 - see also the discussion below.
} 
the shape of the demand curve between and beyond these points (Bateman et al. 2002). We assume that the probability of an individual's WTP being no lower than a price point covered in the survey is equal to the probability of WTP being equal to the next highest price point covered, and we count reported WTP of the maximum price covered in the survey as equal to that amount. We thus estimate users' mean WTP through the following step function

$$
\bar{w}_{A m}=\sum_{p \in P} \theta_{w \geq p}\left(p-p_{j-1}\right) \quad \text { for } \quad p \in P=\{5,10, \ldots, 30\}
$$

with $\theta_{w \geq p}$ denominating the probability of WTP being at least equal to a price, that is, the ratio of the number of respondents accepting the CCS option at a price and the total number of respondents, which ranges between 0 and 1 .

This estimate of mean average WTP, $\bar{w}_{A m}$, in our sample of the Dutch population is $€ 9.25$ per month. That amount is the cautious estimation of the maximum price for a license at which a CCS would pass the Kaldor-Hicks compensation criterion among users, if all individuals were to participate and pay. At this price, aggregate user surplus is zero. Below this price, users are on average better off than under the status quo.

The population of the Netherlands in 2013 was 16.78 million, and average household size was 2.2 according to Eurostat (2014a, b), so that the number of households in the country is about 7.63 million. In 2013, $95 \%$ of the Dutch population aged between 16 and 74 years had Internet access at home. Assuming that all households are equally likely to have Internet access, the relevant number of households with Internet connection is 7.25 million. ${ }^{19}$ Multiplied by average WTP of $€ 9.25$ per month and 12 months per year, the aggregate WTP of users for the CCS is $€ 804.8$ million per year.

The main CMO concerned with recorded music in the Netherlands, Buma/ Stemra, has had a net distribution ratio of ca. $95 \%$ in 2012, including allocations for social and cultural purposes. This is high by international standards, but it is probable that CMO's monitoring and enforcement costs of a CCS would be low compared to royalties from mechanical reproduction or public performance rights, for example. ${ }^{20}$ Overall, the estimated amount that could be distributed among rights holders would thus be in the order of $€ 764.6$ million.

Industry statistics provide us with a reasonable indication of rights holder income under the status quo, $I_{S}$. For the year 2012, the most recent report of the IFPI (2013) estimates rights holder revenues in the market for recorded music in the Netherlands

\footnotetext{
19 This is a rough estimation. Besides the simplifying assumption that households of all sizes are equally likely to have an Internet subscription, we do not control for a probable greater proportion of individuals younger than 15 (that were not included into the survey but may have increased older cohabitants' WTP) in multi-person households, or for multiple places of residence with Internet subscription.

20 This estimate of the operating cost of a CCS, $B$, as a fixed percentage of the collected sum has the advantage of being simple and related to observed operating costs. It has the disadvantage that it treats CCS operating costs as variable, when it is highly probable that there are high fixed costs and low variable costs in operating a CCS.
} 
at $€ 143.6$ million. ${ }^{21}$ For lack of better data, we assume that a CCS substitutes for all conventional purchases of recorded music.

An adequate CCS that is mandatory on the user side could thus increase rights holder revenues by up to ca. $€ 621$ million, without making users at large worse off.

A mandatory CCS would be most acceptable if neither users nor rights holders were worse off in the short run. So far, we have discussed the upper bound of this range of the price for a mandatory CCS, where the price is equal to mean user WTP so that there is no effect on aggregate user welfare. The lower bound is found at the monthly price, $p_{e}$, at which a mandatory CCS would generate annual rights holder revenues equal to current rights holder revenues from selling recorded music to private households in the Netherlands ${ }^{22}$

$$
p_{e} \equiv p N d=\frac{I_{S}}{12}
$$

where $I_{S}$ current rights holder revenues reported on an annual basis, and $d$ is the proportion of the collected CCS fees distributed after covering CCS operating costs, assumed to be $95 \%$. Assuming the number of Internet subscriptions, $N$, is unaffected, a CCS fee of ca. $€ 1.74$ per household with Internet subscription would generate the same revenues to rights holders as current revenues in the Dutch market for recorded music.

Overall, there is a wide range of mandatory CCS fees between $€ 1.74$ and $€ 9.25$ in which both users and rights holders would be better off compared to the status quo.

Table 2 provides an overview of the effects of the mandatory CCS option for various prices. Since we assume the operating costs of the CCS increase in the collection sum, the total effect on social welfare decreases with revenues to rights holders (and thus price). Prices higher than average WTP would not be desirable, since they would lead to excessive allocation of resources to the creation of recorded music.

\subsection{A voluntary compensation system}

With a voluntary CCS, there is no negative effect on user welfare, as low-WTP users do not participate. The total effect on user welfare is then

\footnotetext{
21 The IFPI (2013) reports revenues at "trade value" from the physical market for recorded music of US\$125.2 and for the digital market of US\$58.9. We recalculate to $€$ using the exchange rate of 0.78 reported in IFPI (2013). The IFPI data are derived from data reported by NVPI (2013), which estimates total revenues at retail value in the Dutch market for recorded music at $€ 189.6$ in 2012 . The direction of our results also holds using these retail values.In the Netherlands, a copying levy on ICT hardware collected just over $€ 5.3$ million (WIPO 2013) in 2012. Collected sums for 2013 were substantially higher ( $>€ 20$ million), and some of this is distributed among rights holders to recorded music. For lack of precise data, we do not incorporate these revenues into our analysis, so that our results relate to a situation in which the copying levy would coexist with a CCS regarding Internet subscription. Given the modest size of the copying levy revenues for music rights holders, it would not affect the general direction of our results if copying levies were replaced by a CCS regarding Internet subscriptions.

22 We ignore purchases of recorded music by the $5 \%$ of Dutch households without Internet connection that would not be directly affected by a CCS.
} 
Table 2 Summary of results for a mandatory compensation system

\begin{tabular}{|c|c|c|c|c|c|}
\hline \multicolumn{2}{|l|}{$p$ CS fee $(€ /$ month $)$} & $\begin{array}{l}\theta_{w>p} \\
\text { Probability } \\
\text { of WTP } \\
\text { exceeding } p\end{array}$ & $\begin{array}{l}\Delta \pi_{R A m} \\
\text { Change in rights } \\
\text { holder revenues } \\
(€ \text { million/year) }\end{array}$ & $\begin{array}{l}\pi_{U A m} \\
\text { Aggregate effect } \\
\text { on user welfare } \\
(€ \text { million/year) }\end{array}$ & $\begin{array}{l}\Pi_{A m} \\
\text { Combined } \\
\text { welfare effect }^{\mathrm{a}} \\
(€ \text { million/year })\end{array}$ \\
\hline \multirow{6}{*}{$\begin{array}{l}\text { Price points covered } \\
\text { in the choice } \\
\text { experiment }\end{array}$} & 5 & 0.4532 & 269.66 & 370.07 & 639.73 \\
\hline & 10 & 0.3892 & 682.91 & -64.93 & 617.98 \\
\hline & 15 & 0.3287 & 1096.16 & -499.93 & 596.23 \\
\hline & 20 & 0.2734 & 1509.41 & -934.93 & 574.48 \\
\hline & 25 & 0.2244 & 1922.66 & -1369.93 & 552.73 \\
\hline & 30 & 0.1819 & 2335.91 & -1804.93 & 530.98 \\
\hline $\bar{w}_{A m}$ & $9.25^{\mathrm{b}}$ & & 621.23 & 0 & 621.23 \\
\hline \multicolumn{6}{|l|}{ Mean WTP } \\
\hline$p_{e}$ & 1.74 & & 0 & 653.92 & 653.92 \\
\hline $\begin{array}{l}\text { Price at which } \\
\text { rights holders are } \\
\text { fully compensated }\end{array}$ & & & & & \\
\hline
\end{tabular}

Based on 7.25 million Dutch households with Internet connection; assuming complete substitution of conventional record industry revenues of $€ 164.7$ million per year by the CS; assuming a distribution rate of CCS revenues of $95 \%$

a Without deducting $5 \%$ CCS operating costs of collected fees, combined welfare is constant at $€ 653.92$ million between a CCS fee of $€ 1.74$ and $€ 30$ per month

${ }^{\mathrm{b}}$ Using the lower bounds of the $95 \%$ confidence intervals of $\theta_{w \geq p}$ for each price point covered in the choice experiment, mean WTP is $€ 9.01$. Using the upper bound, mean WTP is $€ 9.50$

$$
\pi_{U A v}=\left(\bar{w}_{h}(A)-p\right) D_{v}(p, A)
$$

where subscript $v$ stands for voluntary and $D_{v}$ for the demand for a voluntary CCS license, which is equivalent to the number of rights holders with a WTP greater than the price of this license, $n_{h}$. For simplicity, we present this as Eq. 2 without the lowWTP users. Of course, at any given price and CCS option, the number of voluntarily participating users and their mean WTP will not be the same as in a mandatory system, due to any effect of the mandatory/voluntary attribute on WTP, for instance if users value the option of cancelling the CCS in principle or in case their preferences change.

The number of participating users with a voluntary CCS will be lower than with a mandatory CCS, since low-WTP users can opt out. Rights holder revenues with a voluntary CCS on the user side associated with Internet subscription are

$$
I_{A v}=p D_{\mathrm{v}}(p, A, X)-B
$$

Here, Internet subscription and the CCS are not necessarily bundled, so that $X$ affects the maximum number of users participating in the CCS and is otherwise irrelevant for the number of CCS participants. A voluntary CCS can only increase demand for Internet subscription, if the CCS does not adversely affect the supply of creative works in the long run. 
The overall effect of a voluntary CCS on social welfare, $\Pi_{A v}$, is

$$
\begin{aligned}
\Pi_{A v} & =\pi_{U A v}+\Delta \pi_{R A v} \\
& =\left(\bar{w}_{h}(A)-p\right) D_{v}(p, A, X)+p n_{h}(p, A)-I_{S}-C_{A v}+C_{S}-B
\end{aligned}
$$

A monopolistic CMO administering a CCS would set the profit-maximizing price of the online license for recorded music. We continue focussing on the short run, over which the costs of creating new copyright works is irrelevant. The operating costs of a CCS are uncertain. We thus estimate the revenue-maximizing price of a CCS charged among voluntary users.

The discrete choice experiment produced probabilities of a respondents' WTP exceeding, $\theta_{w \geq p} \mid \theta \in 0, \ldots, 1$, for six price points. We use linear OLS regression of these probabilities and price to describe the relationship of voluntary participation in a CCS and price as $\theta_{w \geq p}=\alpha-\beta p$. Multiplying by the size of the relevant population, we get a linear demand function within the range of prices covered in the choice experiment of the shape ${ }^{23}$

$$
D_{A v}=(\alpha-\beta p) N
$$

With this linear model of demand, the revenue-maximizing price, $p^{*}$, for a voluntary CCS license is found at

$$
p *=\frac{-\alpha}{2 \beta}
$$

The monthly price at which a voluntary CCS would fully compensate rights holders for complete substitution of conventional purchases by CCS users, $p_{e}$, is

$$
p_{e} \equiv p \theta_{w \geq p} N d=\frac{I_{S}}{12}
$$

As in Eq. 9, we include a measure of $I_{S}$ per year as this tends to be the only data that are reliably available. Assuming that there is no correlation between WTP for a CCS and conventional purchasing, $p_{e}$ is a constant across all CCS options covered in this paper at ca. $€ 1.74 .^{24}$

The revenue-maximizing price, $p *$, falls between prices for which we have empirical estimates. To estimate $p *$, we use the linear regression of price points

\footnotetext{
23 This results in $R^{2}=.995$, so that little is gained from fitting alternative regression models.

${ }^{24}$ It is not clear whether there should be a positive or negative correlation between WTP for a CCS and conventional purchasing. On the one hand, taste for music is positively related with WTP for a CCS and with conventional music purchasing. On the other hand, conventional purchasing is very probably an indication of a preference for this way of accessing recorded music over unauthorized copying. Much of this preference for conventional purchases should remain in case a CCS offers a legal license for copying and use of copyright works online, since in the Netherlands there is hardly any enforcement against private copying from unlawful sources under the status quo. In any case, our basic result - that there is a range of CCS options and prices over which rights holder revenues and user welfare would simultaneously be greater than in the current situation-holds even in the extreme case of complete substitution by voluntary CCS for all conventional purchases (i.e., a complete substitution and perfect correlation between voluntary participation in a CCS and music purchasing).
} 
covered in the choice experiment and the respective probabilities of participation, $\theta_{w \geq p}$; see the documentation in notes (2) of Table 3. We estimate the average WTP, $\bar{w}_{h A v}$, of users with a WTP greater than $p *$ through the following step function

$$
\bar{w}_{h A v}=\sum_{p \in P} \theta_{w>p}\left(p-p_{j-1}\right) \quad \text { for } \quad p \in P=\{5,10, \ldots, p *, \ldots, 30\} \geq p *
$$

For a voluntary CCS with a flat monthly fee and no changes to the strength of copyright enforcement, the revenue-maximizing price, $p^{*}$, is $€ 23.43$, at which $24.53 \%$ of the sample would purchase. If this amount were collected per voluntarily participating household with Internet subscription, total revenues would be $€ 500.2$ million.

Deducting $5 \%$ operating costs of the CCS, the amount distributed among rights holders would be $€ 475.2$ million. This is more than three times current revenues to the recorded music industry of $€ 143.6$ million, not all of which would be substituted by a voluntary CCS in which only a minority of households participates. Assuming conservatively that the CCS would substitute for all conventional music purchases among participating users and that WTP for a CCS and music purchasing are uncorrelated, this voluntary CCS would increase rights holder revenues by $€ 439.9$ million.

At the "fully compensating" price, $p_{e}, \mathrm{CCS}$ revenues for rights holders would be equal to current revenues in the market for sound recordings (assuming complete substitution for conventional purchases among all CCS users and no correlation between the probability to participate in a CCS and conventional purchasing). Results for this price point as reported in Table 3 for the voluntary CCS option require some explanation. The price $p_{e}$ falls below the range of price points covered in the survey. We thus assume conservatively that the participation rate is equal to the lowest price point covered, €5, and that the mean WTP of users with a WTP greater than $p_{e}$ is equal to the mean of the entire sample, including low-WTP users. This explains the low estimates of user welfare and combined welfare at $p_{e}$. Assuming the approximately linear, inverse relationship between price and participation rate we find for the empirically assessed price points were to hold between $p_{e}$ and $€ 5$, aggregate user welfare would be much larger and combined welfare would exceed that for any other price point. The results for the mandatory CCS option illustrate this: There, no estimate of the probability of acceptance is required, and combined welfare at $p_{e}$ exceeds the value for all other price points.

At a CCS fee of $€ 5$ per month, $44.6 \%$ of the respondents would voluntarily participate in a CCS without greater copyright enforcement. Except for our conservative estimate of the values at $p_{e}$ - see above-the combined welfare effect of a CCS strictly decreases with price. That could be offset by any supply effect in the long run, which is not included in the analysis, except in the sense that respondents may have incorporated their own expectations of long-term consequences into their evaluation of the CCS proposals. Another way to put this is that our data from the discrete choice experiment may not fully reflect the costs of creating new copyright works and the depreciation of the existing stock of copyright works. 
Table 3 Summary of results for a voluntary compensation system with no changes to copyright enforcement

\begin{tabular}{|c|c|c|c|c|c|c|}
\hline \multicolumn{2}{|c|}{$\begin{array}{l}p \\
\text { Monthly CCS fee }(€)\end{array}$} & $\begin{array}{l}\theta_{w \geq p} \\
\text { Probability } \\
\text { of } \\
\text { participation }\end{array}$ & $\begin{array}{l}\bar{w}_{h} \\
\text { Mean WTP of } \\
\text { participating } \\
\text { users } \\
(€ / \text { month })\end{array}$ & $\begin{array}{l}\Delta \pi_{R A m} \\
\text { Annual } \\
\text { change in } \\
\text { rights holder } \\
\text { revenues } \\
(€ \text { million/ } \\
\text { year })\end{array}$ & $\begin{array}{l}\pi_{U A m} \\
\text { Aggregate } \\
\text { effect on } \\
\text { user } \\
\text { welfare } \\
\text { (€ million/ } \\
\text { year) }\end{array}$ & $\begin{array}{l}\Pi_{A m} \\
\text { Combined } \\
\text { welfare } \\
\text { effect } \\
(€ \text { million/ } \\
\text { year) }\end{array}$ \\
\hline \multirow{6}{*}{$\begin{array}{l}\text { Price points } \\
\text { covered in the } \\
\text { choice } \\
\text { experiment }\end{array}$} & 5 & 0.434 & 20.66 & 120.37 & 608.35 & 728.72 \\
\hline & 10 & 0.373 & 23.16 & 262.96 & 440.85 & 703.80 \\
\hline & 15 & 0.316 & 25.49 & 358.62 & 298.53 & 657.15 \\
\hline & 20 & 0.264 & 27.52 & 413.72 & 179.30 & 593.02 \\
\hline & 25 & 0.218 & 29.09 & 435.93 & 80.68 & 516.60 \\
\hline & 30 & 0.178 & 30 & 433.22 & $0^{\mathrm{a}}$ & 433.22 \\
\hline$p^{*}$ & $23.42^{\mathrm{b}}$ & $0.2368^{\mathrm{b}}$ & $28.85^{\mathrm{b}}$ & $439.94^{\mathrm{c}}$ & $111.92^{\mathrm{c}}$ & $530.00^{\mathrm{c}}$ \\
\hline \multicolumn{7}{|l|}{$\begin{array}{l}\text { Revenue- } \\
\text { maximizing } \\
\text { price }\end{array}$} \\
\hline$p_{e}$ & 1.74 & $0.4464^{\mathrm{d}}$ & $9.22^{\mathrm{d}}$ & 0 & $>290.77^{\mathrm{e}}$ & $>290.77^{\mathrm{e}}$ \\
\hline \multicolumn{7}{|l|}{$\begin{array}{l}\text { Price at which } \\
\text { rights holders } \\
\text { are fully } \\
\text { compensated }\end{array}$} \\
\hline
\end{tabular}

Based on 7.25 million Dutch households with Internet connection; assuming complete substitution of conventional record industry revenues for all users participating in the CS; assuming a distribution rate of CCS revenues of $95 \%$

${ }^{a}$ No WTP greater than $€ 30$ could be recorded by respondents. The zero reported here is an artifact of that. This cap may lead to an underestimation of user welfare, $\pi_{U A m}$. The advantage is that we limit the potential for high "protest bids"

${ }^{\mathrm{b}}$ We derive the revenue-maximizing price — and the probability of voluntary participation at this pricefrom the results of a linear regression of the six price points covered in the choice experiment and the respective probabilities of a participation, $\theta_{w \geq p}$, which results in $\theta_{w \geq p}=0.49075-0.01047 p$, with an $R^{2}=0.995$. For simplicity, we report results for that price point that maximizes the collection sum of the CCS

${ }^{c}$ Since we are using a step function to calculate the effect of a CCS on user welfare and rights holder income (see Eq. 16), the results reported here are somewhat below maximal revenues based on regression results

${ }^{d}$ Rather than extrapolating beyond the price range covered in the choice experiment, we use $\theta_{w \geq p}$ for the lowest price covered, $€ 5$ (following Bateman et al. 2002). Since demand is very probably a strictly decreasing function, we thus underestimate $\theta_{w \geq p}$ at $p_{e}$

${ }^{\mathrm{e}}$ We report $\bar{w}_{h}$ for the lowest price point included into the choice experiment, $€ 5$; $\bar{w}_{h}$ for $€ 1.74$ should range between the mean for the entire sample, $\bar{w}$, of $€ 9.224$, and $\bar{w}_{h}$ for $€ 5, € 20.66$. That is, user welfare, $\pi_{U A m}$, and the combined welfare effect, $\Pi_{A m}$, at $p_{e}$ are probably substantially higher. If $\theta_{w \geq p}$ is strictly increasing in price over the lower price range not covered in the choice experiment, $\Pi_{A m}$ at $p_{e}$ is greater than at $€ 5$ ( $€ 728.72$ million)

The desirable range of prices for a voluntary CCS is ca. $€ 1.74-€ 23.43$ per month. Even at the upper bound that maximizes the collection amount of the CCS for rights holders, some user surplus remains, but the participation rate is low $(24.5 \%)$. 
Table 2 and Fig. 2 display the participation probabilities for the voluntary CCS option under two treatments: one with and one without greater copyright enforcement. There are no significant differences. Therefore, we do not present separate estimates of the CCS option with greater copyright enforcement. With an affordable voluntary CCS available, there would be stronger moral justification for copyright enforcement among users opting out. Our results do indicate, however, that investments in stronger enforcement are not essential to make a voluntary CCS "work" in the sense that rights holder revenues are increased without making users

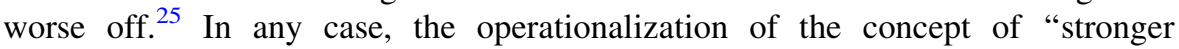
copyright enforcement" in the choice experiment was challenging and the instructions to respondents eventually left relatively great scope for varied interpretation.

Comparing the voluntary with the mandatory CCS options, the greater flexibility and adaptability of a voluntary CCS comes at a price for rights holders: Prospective CCS revenues to rights holders are lower with the voluntary option. Nevertheless, the voluntary CCS could increase rights holder revenues up to a factor of three. User welfare and combined welfare tend to be greater with a voluntary option, at least up to a price of $€ 15$. These results also suggest that the main long-run problem identified with CCS by economists so far-the offsetting of the coordination of supply and demand through prices—can be mitigated through a voluntary CS.

With a voluntary CCS and revenue-maximizing pricing, about three quarters of the population of users would not participate in the CCS, and the prospective participation rate never exceeds $50 \%$ for any price point empirically assessed. A voluntary CCS would thus have the disadvantage that illegitimate use would very probably still occur frequently, which could be costly to society.

\section{Extensions and limitations}

This paper is focused on the direct effects of a CCS on the position of the immediate stakeholders in the market for recorded music, users, and rights holders. Due to a lack of valid information on costs, the focus is on revenues rather than profits regarding the rights holder position. This does not cover all important consequences of a CCS. We discuss further effects here (for a more extensive discussion, see Handke 2014).

\subsection{Costs for rights holders}

There is little valid information on production costs and transaction costs suffered by rights holders. However, it is probable that a CCS reduces a number of rights holder costs. Compared to the market for physical sound carriers, there are no costs of manufacturing, distribution of physical goods, and excess production or lost sales

\footnotetext{
25 The intuition is that the treatment of "stricter copyright enforcement" could have invoked some protest zeros and/or strategic responses, which could have biased the evaluation of CCS options downwards under this treatment.
} 
due to false predictions of demand for specific works. Compared to the current markets for digital downloads and streams, the costs of enforcing copyrights will fall with a CCS. Furthermore, if peer-to-peer dissemination of music would increase even more with a CCS, the costs of retailing and distribution on the professional supplier side could also decrease. On the other hand, it is not apparent that any costs for rights holders would increase (estimates of CCS operating costs are already included into our calculations). It seems clear that the costs suffered by the rights holder would not be greater with a CCS than at the status quo, $C_{A} \leq C_{S}$.

However, an effective system of measuring use of works online seems essential for a CCS. Among rights holders and in the short-run analysis, any distortion in the distribution of revenues with a CCS compared to direct transactions cancels out if all revenues in excess of the operating costs of the CCS are distributed. In the long run, a distorted distribution of revenues could adversely affect incentives to invest in high-quality works. The main difference to monitoring associated with enforcement of copying restrictions is that this assessment could occur without an adversarial approach and could be restricted to an anonymized sample of the population of CCS users.

\subsection{Long-term effects on the supply of recorded music}

It is improbable that the participants in our choice experiment fully incorporated the long-run effects on the supply of recorded music when evaluating CCS options. For example, there may be a tendency to underestimate changes in the quantity and quality of works supplied and in particular the flow of new works introduced to the market. The greatest promise of an adequate CCS - that would make rights holders better off than the status quo-is that it could trigger additional investments in creativity, mitigating market failure in the provision of quasi-public goods compared to current market conditions with frequent, uncompensated unauthorized use. A CCS that provides a relatively simple and general standard way of managing copyrights on the Internet could also remove barriers to entry for new services regarding the dissemination and use of music online; see Sect. $6.5 .^{26}$

Furthermore, less legal restrictions on the use of music online could trigger taste formation regarding music (Caves 2000; Towse 2003; Ginsburgh and Throsby 2006), learning about existing related technologies and foster user innovation. It is unlikely that the choice experiment fully captures such long-term effects.

\subsection{Price discrimination and product differentiation}

For simplicity, we focus on a standard license with a uniform price set per household with Internet subscription. Price discrimination and product differentiation could improve the social welfare effect of a CCS.

\footnotetext{
${ }^{26}$ For some preliminary evidence on substantial transaction costs in the clearing of copyrights for online music services, see KEA (2012).
} 


\subsection{Effects on other music purchases}

We lack information in particular on the substitution of a CCS for conventional purchases of recorded music. Credible cross-elasticities of demand between a CCS and conventional purchases are difficult to establish in a survey. We thus take the conservative approach of assuming perfect substitution-any CCS users would never purchase recorded music on physical carriers, paid-for downloads or streams, or pay for subscription services. In practice, the substitution rate will not be $100 \%$, so that our estimates of the welfare gain of CCS are underestimated in this respect. ${ }^{27}$

Furthermore, we do not address effects on markets for related goods and services supplied by music rights holders. The live music business is estimated to generate much greater revenues than recorded music. It is improbable that a CCS would have a strong adverse effect on demand for live music or commercial music licensing.

\subsection{Retailing and other dissemination of recorded music}

This section is focused on enterprises disseminating downloads or streams of copyrighted works online or providing closely related services, not traditional retailers selling works on physical sound carriers. ${ }^{28}$ When data were collected, unauthorized copying and use of musical recordings were common in the Netherlands, and a substantial share of record industry revenues in the Netherlands came from Internet-based, authorized retailers of recorded music. The WTP reported in this study reflects the additional expected user value of a CCS compared to a status quo with authorized commercial music services online, including music subscription services.

Commercial enterprises disseminating works online fall into two categories: First, firms that operate under a licensing agreement with rights holders such as the iTunes store, Spotify, or Youtube (authorized digital retailers); second, enterprises that facilitate the dissemination of works online without authorization from rights holders such as "peer-to-peer" networks, BitTorrent sites, and file hosters ("unlawful sources" or unauthorized disseminators). With a CCS, information on unauthorized use needs to be considered to avoid gross inefficiencies in the distribution of revenues. If so, unauthorized use would raise revenues to rights

\footnotetext{
27 A caveat is that when estimating the substitution effect of a voluntary CCS, we assumed no correlation between conventional music purchasing and WTP for a CCS. Purchasing of recorded music is highly concentrated on a minority of individuals, and frequent buyers of recorded music could be more likely to opt-in to a voluntary CCS. For the voluntary CCS option, the substitution for conventional purchases might then be even higher than our estimate of substitution proportional to the participation rate in the CCS. Note however that users with a taste for music have been found to purchase recorded music in multiple formats (Gopal et al. 2006) and have a higher WTP for authorized copies (e.g., Rob and Waldfogel 2006).

28 Regarding retailers of physical sound carriers, this segment of the market has been declining for a long time. A CCS that makes Internet-based dissemination of copyright works more efficient would aggravate this and speed up the "digitization" of the market for recorded music, with physical sound carriers being relegated even more rapidly to a niche of collectibles and high-value users. Traditional retailers would face even more rapidly declining demand, digital retailers at large would face greater demand, and users as well as rights holders could gain from interaction through a less costly intermediation system.
} 
holders roughly proportional to the scale and scope of use of specific works. This will make rights holders less likely to struggle against unauthorized use-or lobby governments to do so-depending on the CCS price and revenue distribution method.

A CCS has three basic effects for online disseminators. First, fees charged by rights holders for authorization of such services will fall. A CCS generates income to rights holders from online dissemination of works independent of more direct payments from online disseminators. Subject to the CCS revenues and distribution scheme, it will thus be rational for rights holders to charge lower fees for the rights to disseminate works online. According to our results, it is possible to set a CCS price so that users and rights holders are both on average better off than under the status quo, even if rights holders do not charge online disseminators at all. Second, a CCS reduces transaction costs by defining standard terms for online dissemination of works. Third, it facilitates market entry and promotes competition between enterprises disseminating works online.

Standard terms of trade that provide legal certainty and stable conditions for a wide range of music dissemination services would reduce uncertainty and facilitate market entry. Market entry in this context has two meanings. First, it refers to new, for-profit firms entering the market. Second, existing unauthorized services or userled innovation-including those facilitating "peer-to-peer" exchanges-might be incorporated more fully into the market if these activities generate income to rights holders. A CCS thus has the potential to lower barriers to entry for legitimate music dissemination services, which currently tends toward narrow oligopolies or quasimonopolies. Disseminators would have to compete less on their ability to strike relatively good licensing agreements or avoid copyright enforcement measures, and more on offering convenient access to a wide range of music, ways of organizing music collections, recommendation systems and user-user interaction or even usercreator interaction. The market for music retailing services of all types would become more contestable and more focused on services that directly concern end users.

However, in the current legal and political context, it seems highly probable that (1) a distinction and separate treatment of non-private/commercial unauthorized use would be upheld, and (2) non-private use would require explicit consent from rights holders. (The legal conception of "non-private/commercial" often entails not only direct pecuniary income from advertising or fees charged to users, but also considers the scale of unauthorized use and any restrictions on access.) Then, the potential of a CCS to reduce transaction costs and promote competition in digital markets for copyright works would not be fully exploited. The distinction between private and non-private use is hard to make, so that many stakeholders would still suffer from uncertainty. Furthermore, even with a CCS, non-private disseminators of music online would incur the fixed costs of negotiating specific agreements with relevant rights holders (or face legal risks). The alternative is blanket licensing under collective rights management also for commercial use online. That could come about spontaneously or through a compulsory license, such as that in place already in the USA for digital audio transmission, for example (United States Copyright Office 2011). 
Overall, a CCS would probably strongly affect existing music dissemination services online, and it has ambiguous effects for suppliers of such services. On the one hand, a CCS would increase the transparency of the market for recorded music, could reduce the scope for prolonged negotiations and hold-up problems, and the fees charged by rights holders would in all probability fall. On the other hand, the appropriability conditions for current online retailers could become less favorable, reducing commercial incentives to invest in music retailing services. However, there has been an abundant supply of unauthorized streams and downloads online over the last 15 years in spite of the legal risks involved. A CCS could remove some of the legal uncertainty and develop mutually beneficial arrangements between rights holders and disseminators of works. It then seems unlikely that a CCS would diminish the supply of music dissemination services online, and it might even make it more efficient. ${ }^{29}$

\subsection{The effect of demand for Internet subscription and related services}

The direct effect of a voluntary CCS on demand for Internet subscription could only be to increase demand, since a voluntary CCS would simply be another complementary good available for those users with a WTP greater than the price of a CCS license.

By contrast, a mandatory CCS enforces the bundling of a CCS with Internet subscription. With incomplete price discrimination and product differentiation applied to the CCS, a number of potential users could cancel their Internet subscription because of a mandatory CCS. First, this depends on the user fee for the CCS license. We find that a mandatory CCS priced in the reasonable range of $€ 1.74-€ 9.25$ would make at least $45.3 \%$ to $38.9 \%$ of the sample better off, boosting demand for Internet subscription among this sizable minority. Second, due to competition among ISP, prices for Internet subscription (and other services provided online) should be well in the inelastic range. What is more, the cost of Internet subscription (ca. €20 per month) is much greater than any reasonable mandatory CCS fee. The literature on bundling further illustrates that for information goods with low variable costs, bundling tends to increase supplier profits (Belleflamme and Peitz 2010), unless the bundled goods are good substitutes. Overall, it is improbable that a well-designed CCS would have a strong adverse effect on demand for Internet subscription and related services, unless the CCS fee exceeds the reasonable range specified above.

\section{Conclusions}

The results of our choice experiment indicate that a well-designed CCS for recorded music would make users and rights holders better off. A monthly CCS fee of ca. $€ 1.74$ as a surcharge on Dutch Internet subscriptions would raise the same amount

\footnotetext{
29 Standardization of music licensing through a CCS would probably also increase competition among suppliers of musical works (except for competition on the basis of licensing). Then, rights holders who enjoy a relatively strong bargaining position with online retailers under the status quo would benefit less, since under standard CCS arrangements, there is less scope for striking preferential deals.
} 
of revenues to rights holders as the entire revenues in the Dutch market for recorded music in 2012. A conservative estimate of mean WTP reported in our choice experiment is $€ 9.25$ for a mandatory CCS and higher for CCS options that are voluntary on the user side.

Previous reviews of applied contingent valuation methods report mean overestimations of WTP by a factor of up to 3.26. If overestimation in our case would be equal to that amount, our main conclusion regarding the desirability of a CCS holds comfortably. It holds up to an overestimation of ca. 5.3 for both the mandatory and voluntary CCS options. It is particularly noteworthy that a voluntary CCS could increase rights holder revenues compared to the status quo, as voluntary participation on the user side would mitigate some of the problems with centralized pricing for copyright works a CCS does entail. Furthermore, there is the potential that a CCS that increases rights holder profits would foster the supply of new creative works in way that was not foreseen by participants in the choice experiment, making a CCS even more beneficial in the long run.

To be sure, predictions of real market outcomes based on stated preferences remain uncertain. Given our clear results, more involved experimental adoption of a CCS seems worthwhile, as it would provide revealed preference data and illuminate aspects and consequences that a choice experiment cannot gauge: (1) the substitution effect of a CCS license for conventional purchases; (2) the operating costs of a CS; (3) the effect of a CCS on rights holders' costs; or (4) the consequences for barriers to entry in the market for creative works and related goods and services.

It is important to note that this paper does not include the one-off costs of change due to establishing a CCS among stakeholders, nor political considerations or legal restrictions. Neither does it discuss detailed solutions regarding the monitoring of use and the distribution of CCS revenues among rights holders. Therefore, it does not develop a conclusive argument in favor of adopting a CCS. Instead, this paper enables stakeholders and policy makers to make better-informed decisions whether this option should be further explored.

For 15 years, there has been widespread dissatisfaction with the copyright system online. A CCS may be the most viable option to improve this situation. According to our results, there are CCS options that could foster growth in the market for recorded music, and compared to the status quo, the benefits would probably be substantial. Collective administration of copyright in this manner diverges widely from an ideal market. Alluding back to our title, this "trouble" may still be the lesser evil compared to staying stuck with rampant unauthorized and uncompensated use or costly copyright enforcement measures.

Acknowledgments The authors gratefully acknowledge funding by the Netherlands Organisation for Scientific Research (NWO; project number 407-11-050) and indispensable support by CentERdata, the administrator of the Longitudinal Internet Studies for the Social Sciences (LISS) panel. This paper benefitted greatly from comments by the participants of the SERCI Congress 2014, the ACEI Conference 2014, the "A Long Way to the Top" conference at Erasmus School of Culture and Communication and a Workshop on "Cultural Industries" at the Sorbonne, Paris, in 2014. We owe much to our colleagues at the Institute for Information Law (IViR) at the University of Amsterdam and at the department for Arts and Culture Studies / Cultural Economics at Erasmus University Rotterdam, including in particular João Pedro Quintais, Joost Poort and Erwin Dekker as well as to the anonymous reviewers for this journal. 
Open Access This article is distributed under the terms of the Creative Commons Attribution 4.0 International License (http://creativecommons.org/licenses/by/4.0/), which permits unrestricted use, distribution, and reproduction in any medium, provided you give appropriate credit to the original author(s) and the source, provide a link to the Creative Commons license, and indicate if changes were made.

\section{Appendix 1}

\section{See Table 4.}

Table 4 Overview of conjoint attributes, levels, and instructions (translated from Dutch)

\begin{tabular}{|c|c|c|}
\hline Attribute & Attribute levels & Level descriptions (as presented to respondents) \\
\hline \multicolumn{3}{|c|}{ Allowed uses } \\
\hline 1 & Download & $\begin{array}{l}\text { You have the right to download } \\
\text { personal use from anywhere on the Internet }\end{array}$ \\
\hline 2 & Download + share & $\begin{array}{l}\text { Besides downloading, you have the right to Share } \\
\text { anywhere on the Internet as long as you do not do it for a } \\
\text { profit }\end{array}$ \\
\hline 3 & Download + share + modify & $\begin{array}{l}\text { Besides downloading and sharing, you will have the right to } \\
\frac{\text { modify }}{\text { online }} \underline{\text { (i.e., remix, combine) works and share such works }}\end{array}$ \\
\hline
\end{tabular}

Subject matter

$1 \quad$ Music

$2 \quad$ Music + audiovisual works

$3 \quad$ Music + audiovisual works + digital texts

Catalogue completeness

1 Access to an incomplete catalogue

2

Access to everything, but only after a while

3 Access to all works

Monitoring

$1 \quad$ Anonymized monitoring

$2 \quad$ No monitoring
This option covers recorded music in digital form

Besides recorded music, you can use audiovisual works, such as feature films, TV series, and other TV programs

Besides recorded music and audiovisual works, you can use digital versions of print media, such as books and newspaper/magazine articles

Some rights holders may decide not to participate in the compensation system. Their works are not available through the system, and using them is illegal

Some rights holders prefer to wait with the online release of their works till they have broken even through other channels

A certain time after their release, all works will be available in the system, but using them before that is illegal

You have access to all past and present works, as soon as they are published

Your online media use may be monitored and analyzed in an anonymous fashion to account for the use of each work and help achieve a fair distribution of monies

Anonymity will be legally guaranteed; thus, your identity will not be connected to the actions monitored

Legal safeguards ensure that your online media use will not be monitored and analyzed in any fashion within the framework of the ACS 
Table 4 continued

\begin{tabular}{|c|c|c|}
\hline Attribute & Attribute levels & Level descriptions (as presented to respondents) \\
\hline \multicolumn{3}{|c|}{ Distribution of revenues } \\
\hline 1 & Artists share: minimum $50 \%$ & $\begin{array}{l}\text { Regulation will set the share of individual rights holders } \\
\text { (artists, performers, etc.) to at least } 50 \% \text { of the revenues } \\
\text { generated by the compensation system }\end{array}$ \\
\hline 2 & Artists are free to negotiate & $\begin{array}{l}\text { Different rights holders, such as individuals (artist, } \\
\text { performers, etc) and corporations (recording companies, } \\
\text { studios, etc.) will be free to negotiate how they share the } \\
\text { revenues among themselves, without any outside } \\
\text { intervention }\end{array}$ \\
\hline \multicolumn{3}{|l|}{ Price } \\
\hline 1 & $€ 5$ per month & \\
\hline 2 & $€ 10$ per month & \\
\hline 3 & $€ 15$ per month & \\
\hline 4 & $€ 20$ per month & \\
\hline 5 & $€ 25$ per month & \\
\hline 6 & $€ 30$ per month & \\
\hline
\end{tabular}

\section{Appendix 2}

See Table 5.

Table 5 Parameter estimates: conditional logit model of CCS choice

\begin{tabular}{|c|c|c|c|c|}
\hline Attributes & Levels & Mandatory & Voluntary & $\begin{array}{l}\text { Voluntary } \\
\text { stricter }\end{array}$ \\
\hline \multirow[t]{5}{*}{ Allowed uses } & Ref. $=$ download & & & \\
\hline & Download and share & $-0.082 * *$ & $-0.091 * *$ & $-0.159 * * *$ \\
\hline & & $(0.038)$ & $(0.038)$ & $(0.037)$ \\
\hline & Download and share and & $-0.363 * * *$ & $-0.378 * * *$ & $-0.384 * * *$ \\
\hline & modification & $(0.045)$ & $(0.045)$ & $(0.044)$ \\
\hline \multirow[t]{5}{*}{ Subject matter } & Ref. $=$ music & & & \\
\hline & Music and AV & $0.479 * * *$ & $0.449 * * *$ & $0.491 * * *$ \\
\hline & & $(0.040)$ & $(0.040)$ & $(0.039)$ \\
\hline & Music and AV and books & $0.372 * * *$ & $0.344 * * *$ & $0.306^{* * * *}$ \\
\hline & & $(0.047)$ & $(0.046)$ & $(0.046)$ \\
\hline \multirow[t]{5}{*}{ Catalogue completeness } & Ref. $=$ partial catalogue & & & \\
\hline & Temporal restrictions & $0.207 * * *$ & $0.176^{* * *}$ & $0.108 * * *$ \\
\hline & & $(0.039)$ & $(0.038)$ & $(0.038)$ \\
\hline & All works & $0.132 * * *$ & $0.082 *$ & 0.041 \\
\hline & & $(0.045)$ & $(0.045)$ & $(0.045)$ \\
\hline
\end{tabular}


Table 5 continued

\begin{tabular}{|c|c|c|c|c|}
\hline Attributes & Levels & Mandatory & Voluntary & $\begin{array}{l}\text { Voluntary } \\
\text { stricter }\end{array}$ \\
\hline \multirow[t]{2}{*}{ Monitoring } & Ref. $=$ no monitor. & & & \\
\hline & Anonymous monitoring & $\begin{array}{l}-0.204 * * * \\
(0.035)\end{array}$ & $\begin{array}{l}-0.125 * * * \\
(0.035)\end{array}$ & $\begin{array}{l}-0.094 * * * \\
(0.034)\end{array}$ \\
\hline \multirow[t]{2}{*}{ Artists payment } & Ref. $=$ no guarantee & & & \\
\hline & Guarantee & $\begin{array}{l}-0.088 * * \\
(0.035)\end{array}$ & $\begin{array}{l}-0.051 \\
(0.035)\end{array}$ & $\begin{array}{l}-0.016 \\
(0.034)\end{array}$ \\
\hline Price & Price & $\begin{array}{l}-0.053 * * * \\
(0.002)\end{array}$ & $\begin{array}{l}-0.051 * * * \\
(0.002)\end{array}$ & $\begin{array}{l}-0.053 * * * \\
(0.002)\end{array}$ \\
\hline No-choice & No-choice & $\begin{array}{l}0.049 \\
(0.053)\end{array}$ & $\begin{array}{l}0.047 \\
(0.053)\end{array}$ & $\begin{array}{l}-0.100^{*} \\
(0.052)\end{array}$ \\
\hline Nagelkerke $R^{2}$ & & 0.242 & 0.226 & 0.209 \\
\hline Cox-Snell $R^{2}$ & & 0.215 & 0.201 & 0.186 \\
\hline$N$ & & 9748 & 9688 & 9790 \\
\hline
\end{tabular}

Figures within parentheses are SE

$* p<0.1$; ** $p<0.05$; *** $p<0.01$

\section{References}

Aigrain, P. (2008). Internet \& Création. Paris: InLibroVeritas.

Aigrain, P. (2012). Sharing: Culture and the economy in the internet age. Amsterdam: Amsterdam University Press.

Alberini, A., \& Kahn, J. R. (2009). Handbook on contingent valuation. Cheltenham: Edward Elgar.

Arrow, K. J. (1962). Economic welfare and the allocation of resources for invention. In National Bureau of Economic Research (ed.), The rate and direction of inventive activity (pp. 609-625). Princeton: Princeton University Press.

Arrow, K., \& Solow, R. (1993). Report of the NOAA panel on contingent valuation. Washington, DC: National Oceanic and Atmospheric Administration.

Bateman, I. J., et al. (Eds.). (2002). Economic valuation with stated preference techniques: A manual. Cheltenham: Edward Elgar.

Baumol, W. J., \& Bowen, W. G. (1966). Performing arts: The economic dilemma. New York: The Twentieth Century Fund.

Belleflamme, P., \& Peitz, M. (2010). Industrial organization: Markets and strategies. Cambridge: Cambridge University Press.

Besen, S. M., \& Kirby, S. N. (1989). Compensating creators of intellectual property-Collectives that collect. Santa Monica, CA: The RAND Corporation.

Besen, S. M., Kirby, S. N., \& Salop, S. C. (1992). An economic analysis of copyright collectives. Virginia Law Review, 78(1), 383-411.

Blind, K. (2004). The economics of standards-Theory, evidence, policy. Cheltenham: Edward Elgar.

Caves, R. (2000). Creative industries-Contracts between art and commerce. Cambridge, MA: Harvard University Press.

CentERdata. (2014). Longitudinal internet studies for the social sciences. http://www.lissdata.nl/lissdata/

Eckersley, P. (2004). Virtual markets for virtual goods: The mirror image of digital copyright? Harvard Journal of Law and Technology, 18, 85-166.

Entertainment Media Research. (2011). 2011 digital entertainment survey. London: Wiggin LLP.

Eurostat. (2014a). Average household size. Retrieved from: http://appsso.eurostat.ec.europa.eu/nui/show. do?dataset=ilc_lvph01\&lang=en 
Eurostat. (2014b). Population on 1 January. Retrieved from: http://epp.eurostat.ec.europa.eu/tgm/table. do? tab $=$ table \&init $=1 \&$ language $=$ en $\&$ pcode $=$ tps00001\&plugin $=1$

Fetscherin, M. (2009). Importance of cultural and risk aspects in music piracy: A cross-national comparison among university students. Journal of Electronic Commerce Research, 10(1), 42-55.

Fisher, W. W, I. I. I. (2004). Promises to keep-Technology, law, and the future of entertainment. Stanford: Stanford University Press.

Ginsburgh, V. A., \& Throsby, D. (2006). Handbook of the economics of art and culture. Amsterdam: North Holland.

Gopal, R. D., Bhattacharjee, S., \& Sanders, G. L. (2006). Do artists benefit from online music sharing? The Journal of Business, 79(3), 1503-1533.

Haaijer, R., Kamakura, W., \& Wedel, M. (2001). The 'no-choice' alternative in conjoint choice experiments. International Journal of Market Research, 43(1), 93-106.

Handke, C. (2012). A taxonomy of empirical research on copyright-How do we inform policy? Review of Economic Research on Copyright Issues, 9(1), 47-92.

Handke, C. (2014). The economics of collective copyright management. In R. Watt (Ed.), Handbook of the economics of copyright. Cheltenham: Edward Elgar. http://ssrn.com/abstract=2256178

Handke, C., Quintais, J. P., \& Bodo, B. (2013). The economics of copyright compensation systems for digital use. Presentation at the Society for Economic Research on Copyright Issues Annual Congress 2013, Paris, 8-9 July 2013. http://www.serci.org/documents.htm

Handke, C., \& Towse, R. (2007). Economics of copyright collecting societies. International Review of Intellectual Property and Competition Law, 38(8), 937-957.

Harrison, G. W., \& Rutström, E. E. (2008). Experimental evidence on the existence of hypothetical bias in value elicitation methods. Handbook of Experimental Economics Results, 1(5), 752-767.

Hennig-Thurau, T., Hennig, V., \& Sattler, H. (2007). Consumer file-sharing of motion pictures. Journal of Marketing, 71, 1-18.

IFPI / International Federation of the Phonographic Industries. (2013). Record industry in numbers. London: International Federation of Phonographic Industries.

Karaganis, J., \& Renkema, L. (2012). Copy culture in the US and Germany. New York: The American Assembly.

KEA/Vrije Universiteit Brussel. (2012). Licensing music works and transaction costs in Europe. http:// www.keanet.eu/docs/music\%20licensing\%20and\%20transaction\%20costs\%20-\%20full.pdf

$\mathrm{Ku}, \mathrm{R} . \mathrm{S}$. (2002). The creative destruction of copyright: Napster and the new economics of digital technology. University of Chicago Law Review, 69(2002), 263-324.

Lagerkvist, C. J., Carlsson, F., \& Viske, D. (2006). Swedish consumer preferences for animal welfare and biotech: a choice experiment. The Journal of Agrobiotechnology Management \& Economics, 9(1), 51-58.

Lancaster, K. (1966). A new approach to consumer theory. Journal of Political Economy, 74(2), 132-157.

Lancaster, K. (1971). Consumer demand: A new approach. New York: Columbia University Press.

Landes, W. M., \& Posner, R. A. (1989). An economic analysis of copyright law. Journal of Legal Studies, 18(2), 325-363.

Liebowitz, S. (2003). Alternative copyright systems: The problems with a compulsory license. http:// www.utdallas.edu/ liebowit/intprop/complpff.pdf

Liebowitz, S. J. (2005). MP3 s and copyright collectives: A cure worse than the disease? In W. Gordon, L. Takeyama, \& R. Towse (Eds.), Developments in the economics of copyright: Research and analysis (pp. 37-59). Cheltenham: Edward Elgar.

Liebowitz, S. J., \& Watt, R. (2006). How best to ensure the remuneration of creators in the market for music? Copyright and its alternatives. Journal of Economic Surveys, 20(4), 513-545.

List, J. A., \& Gallet, C. A. (2001). What experimental protocol influence disparities between actual and hypothetical stated values? Evidence from a meta-analysis. Environmental \& Resource Economics, 20, 241-254.

Little, J., \& Berrens, R. (2004). Explaining disparities between actual and hypothetical stated values: Further investigation using meta-analysis. Economics Bulletin, 3(6), 1-13.

Loureiro, M. L., \& Umberger, W. J. (2007). A choice experiment model for beef: What US consumer responses tell us about relative preferences for food safety, country-of-origin labeling and traceability. Food Policy, 32(4), 496-514.

Lunney, G. S, Jr. (2001). The death of copyright: Digital technology, private copying, and the digital millennium copyright act. Virginia Law Review, 87(2001), 813-920. 
McFadden, D. (1974). Conditional logit analysis of qualitative choice behavior. In: Zarembka, P. (Ed.), Frontiers in Econometrics. New York: Academic Press, 105-142.

Merges, R. P. (2004). Compulsory licensing vs. the three 'Golden Oldies'-Property rights, contracts, and markets. Cato Policy Analysis, 508. http://www.cato.org/sites/cato.org/files/pubs/pdf/pa508.pdf

Modot, A., Fontanel, H., Garnett, N., Lambert, E., Chaubeau, A., Chung, J., \& Jalladeau, P. (2011). The "Content Flat-Rate": A solution to illegal file-sharing? Study for the European Parliament's Committee on Culture and Education. Brussels: European Parliament.

Murphy, J. J., Allen, P. G., Stevens, T. H., \& Weatherhead, D. (2005a). A meta-analysis of hypothetical bias in stated preference valuation. Environmental \& Resource Economics, 30(3), 313-325.

Murphy, J. J., Stevens, T., \& Weatherhead, D. (2005b). Is cheap talk effective at eliminating hypothetical bias in a provision point mechanism? Environmental \& Resource Economics, 30(3), 327-343.

National Oceanic and Atmospheric Administration/NOAA. (1996). Natural resource damage assessments: Final rules. Federal Register, 61, 439. January 5, 1996.

Netanel, N. W. (2003). Impose a noncommercial use levy to allow free peer-to-peer file sharing. Harvard Journal of Law and Technology, 17, 2-84.

Noonan, D. S. (2003). Contingent valuation and cultural resources: A meta-analytic review of the literature. Journal of Cultural Economics, 27(3-4), 159-176.

Novos, I. E., \& Waldman, M. (1984). The effects of increased copyright protection: An analytic approach. Journal of Political Economy, 92, 236-246.

NVPI/Nederlandse Vereniging van Producenten en Importeurs van beeld- en geluidsdragers. (2014). Audiomarkt 2012. http://www.nvpi.nl/sites/default/files/nvpi-marktinformatie-audio-2012.pdf

Peitz, M., \& Waelbroeck, P. (2006). Piracy of digital products: A critical review of the theoretical literature. Information Economics and Policy, 18(4), 449-476.

Quintais, J. P. (2013). A shifting copyright zeitgeist: Alternative compensation models for digital content sharing. Amsterdam: Institute for Information Law (IViR), University of Amsterdam.

$\mathrm{R}$ Core Team. (2014). R: A language and environment for statistical computing- $R$ Foundation for Statistical Computing. Vienna, Austria. http://www.R-project.org/

Rob, R., \& Waldfogel, J. (2006). Piracy on the high C's: Music downloading, sales displacement, and social welfare in a sample of college students. Journal of Law and Economics, 49(1), 29-62.

Rochelandet, F., \& le Guel, F. (2005). P2P music sharing networks: Why the legal fight against copies may be inefficient. Review of Economic Research on Copyright Issues, 2(2), 69-82.

Spindler, G. (2013). Rechtliche und Ökonomische Machbarkeit einer Kulturflatrate. Gutachten erstellt im Auftrag der Bundestagsfraktion „Bündnis 90/DIE GRÜNEN“. Berlin: Bundestag. http://www. gruene-bundestag.de/fileadmin/media/gruenebundestag_de/themen_az/medien/Gutachten-FlatrateGrueneBundestagsfraktion__CC_BY-NC-ND_.pdf

Telser, H., \& Zweifel, P. (2002). Measuring willingness-to-pay for risk reduction: an application of conjoint analysis. Health Econonmics, 11(2), 129-139.

Throsby, D. (2003). Determining the value of cultural goods: How much (or how little) Does contingent valuation tell us? Journal of Cultural Economics, 27(3-4), 275-286.

Towse, R. (Ed.). (2003). A handbook of cultural economics. Cheltenham: Edward Elgar.

Towse, R., Handke, C., \& Stepan, P. (2008). The economics of copyright law: A stocktake of the literature. Review of Economic Research on Copyright Issues, 5(1), 1-22.

Train, K. E. (2003). Discrete Choice Methods with Simulation. 2nd ed. Cambridge (UK): Cambridge University Press.

United States Copyright Office. (2011). Compulsory license for making and distributing phonorecords. Washington, DC: Library of Congress.

Watson, S. J., Zizzo, D. J., \& Fleming, P. (2014). Determinants and welfare implications of unlawful file sharing: A scoping review. CREATe working paper 14/5. http://www.create.ac.uk/wp-content/ uploads/2014/04/Working-Paper-2014-15.pdf

Watt, R. (2000). Copyright and economic theory: Friends or Foes?. Cheltenham: Edward Elgar.

WIPO/World Intellectual Property Organization. (2013). International survey on private copying. Geneva: WIPO. 